\title{
Practical Management of Common Skin Injuries, Lacerations, Wounds, Trigger Fingers, and Burns
}

\author{
Ronald K. Akiki, BA and Raman Mehrzad, MD, MHL, MBA
}

Primary care clinicians encounter many conditions during their day-to-day visits with patients. A few of these common presentations include burns, lacerations, trauma to the hand, and wounds, some of which do not require an evaluation by a specialist and can be managed outpatient by primary care clinicians. In this article, we share evidence-based tips to avoid common pitfalls in primary care recognition and management of such presentations as well as guide them to manage many of these conditions themselves. We also provide guidance in the decision to refer the patient to a plastic surgeon or other specialists. (J Am Board Fam Med 2020;33:799-808.)

Keywords: Ambulatory Care Facilities, Burns, Clinical Medicine, Emergency Medicine, Evidence-Based Medicine, Lacerations, Primary Health Care

\section{Introduction}

Burns, lacerations, and wounds are commonly encountered by primary care clinicians. Health care providers see presentations that may involve hand burns, trigger finger, hand lacerations, and wound complications. ${ }^{1}$ Some of these conditions or procedures and managements referred to plastic surgeons could be performed by a primary care clinician. In this article, we share evidence-based tips to help primary care clinicians avoid common pitfalls in recognition and management of such presentations. We also provide guidance in their decision to refer the patient to a plastic surgeon or other specialists.

\section{Hand and Upper-Extremity Burn Management}

Burns to the hands and upper extremity are a common presentation in the outpatient setting ${ }^{2}$ and have a low threshold for admission to the hospital, especially in young children. ${ }^{3}$ In general, burns are

This article was externally peer reviewed.

Submitted 10 January 2020; revised 21 April 2020; accepted 26 April 2020.

From the Department of Plastic and Reconstructive Surgery, Rhode Island Hospital, The Warren Alpert Medical School of Brown University, Providence, RI.

Funding: None.

Conflict of interest: None.

Corresponding author: Raman Mehrzad, MD, MHL, MBA, Rhode Island Hospital, Warren Alpert Medical School of Brown University, 235 Plain St, Providence, RI 02305 (E-mail: raman_m1@hotmail.com). classified as superficial, partial-, or full-thickness burns. ${ }^{4}$ The first step is to assess the burn depth. Burn depth is classified into 1 of 3 types (superficial, partial-thickness, and full-thickness burns) based on how deeply into the epidermis or dermis the injury might extend. Diagnosis can be made clinically by inspection and palpation. ${ }^{5}$

- Superficial burns present similarly to a bad sunburn, with erythema that blanches with pressure, pain, and dryness. The burn involves the epidermis only and heals on its own in 5 to 10 days.

- Partial-thickness burns involve some parts of the dermis and all of the epidermis. The burn will have blisters with a moist, cheesy, white-to-red appearance, the erythema may or may not blanch with pressure.

- A full-thickness burn damages the dermis, epidermis, and may involve the subcutaneous tissue. It will look leathery with a dry and inelastic texture that does not blanch with pressure.

Superficial partial-thickness burns can be managed in the outpatient setting; the blisters act as biological dressings, and if broken, they might get infected. It is thus recommended to protect the blister from any rubbing or pressure with a sterile nonstick gauze lightly wrapped over it. Full-thickness burns should be evaluated by a specialist while superficial burns can be managed by a primary care clinician. ${ }^{4}$ Partial thickness burn management involves using a well-absorbed topical antibiotic such as silver 
sulfadiazine to prevent infections in addition to active mobilization.

The second step in the assessment is to do a full neurovascular examination by checking the radial and ulnar pulses, sensation in the distribution of the radial, median, and ulnar nerves, and a full motor examination by evaluating deeper structures such as the flexor and extensor tendons. Range of motion and mobility are evaluated simultaneously. Indications for referral or urgent treatment in the emergency department include signs of poor perfusion. Poor perfusion equates a capillary refill time greater than 2 seconds, a hand that is cold to touch, or an absence of a Doppler signal. ${ }^{6}$

In the case of nonurgent hand burns, management can be initiated in the outpatient setting at the primary care clinician's office. ${ }^{7}$ Dressings are used to prevent infections and other complications in wound healing. Commonly used dressings include bacitracin, mafenide acetate (sulfamylon), mupirocin (bactroban), sodium carboxymethylcellulose, biobrane, hydrocolloids, polyurethane foam, Xeroform, and antimicrobial silver dressing. ${ }^{7}$

Xeroform is a sterile nonadherent-to-wound-site dressing that contains 3\% bismuth tribromophenate as a deodorizing agent. If the patient is less than 1 year old, vaseline gauze should be used due to its nontoxic and nonirritable properties for this age group. ${ }^{8}$ Vaseline, rather than Xeroform, is recommended for patients under the age of 1 year since $3 \%$ bismuth tribromophenate has been associated with bacteriostatic properties, ${ }^{9}$ possibly related to a delay in growth and microbiome alteration in babies under the age of 1 year. ${ }^{10,11}$ Bacitracin can also be used in cases where contamination is a risk factor, but simple Vaseline in many cases is enough and could also prevent antibiotic resistance. To absorb wound exudate and keep dressings in place, kerlix gauze rolls are the dressing of choice, but they should not be in placed directly over the wound bed. Dressings should be applied to fingers individually.

Mepilex is a frequently used dressing in burns, pressure ulcers, and in any wound resulting in skin loss. It is made of polyurethane foam, which makes it permeable to liquids and microorganisms while maintaining a moist environment for healing. It does not stick to the moist wound, rather to the dry skin surrounding it. This could be used on burns and put on the area for up to 5 days. $^{12}$
For topical medications, bacitracin is the preferred ointment for partial-thickness and superficial abrasions. $^{13}$

Topical antimicrobials have an 8-hour half-life so dressings should be changed twice daily for the first 3 days then once for the following week. ${ }^{14}$

When applying dressings, thickness should not limit the range of motion of the digits and hand. Is the patient able to stretch their hands on their own? Constant stretching is a must for proper healing. Patient should be advised to use their hands when they get the opportunity to and to keep it elevated when not engaging in activities. ${ }^{7}$ No ice or topical steroids are indicated for the initial treatment of minor burns in the hand as this may increase the risk of infection and may impair healing. It is important to remember pain management and tetanus prophylaxis.

Referral to plastic surgery depends on the classification of the burn. Burn classification is primarily defined by body surface area, location, depth, and size. ${ }^{15-17}$

Below are the criteria for immediate transfer to a burn center:

- Partial-thickness burns $>10 \%$ of TBSA.

- Full-thickness burns.

- Burns involving major joints, face, hands, feet, and genitalia.

- Chemical or electrical burns.

- Any burn with inhalation injury or with concomitant trauma that poses greater risk to the patient

- Patients who require special social, emotional, or rehabilitation needs.

When a patient is referred to a burn center it is important to dress the burn in dry nonstick gauze only without any topical agents or moist dressings since the burn is re-evaluated on admission. ${ }^{15}$

\section{Trigger Finger}

With over 200,000 cases per year in the United States, primary care clinicians are likely to encounter patients with symptoms of trigger finger. ${ }^{18}$ Trigger finger is a common presentation to plastic surgery and many patients present without having tried conservative management first. A significant number of patients do well on conservative management such as activity modification, splinting, and short-term nonsteroidal anti-inflammatory drugs.

Trigger finger occurs due to the loss of the smooth flexor tendon in the context of fibrocartilaginous 
metaplasia of the annular pulley's tendon sheath. The thumb and ring fingers are the most commonly affected digits. ${ }^{19}$

Trigger finger is diagnosed clinically. The nodule in the tendon can be palpable and, in some cases, makes an audible click when the triggered digit is extended. Primary care clinicians should begin conservative treatment on diagnosis. This includes activity modification, splinting, and shortterm nonsteroidal anti-inflammatory drugs for triggering in any finger. ${ }^{19}$ If conservative treatment does not help in relieving the symptoms in 4 to 6 weeks, glucocorticoid injection is the next step in management. The exception to this rule is pediatric patients with triggering of the thumb. Studies have shown that glucocorticoid injections in this population did not increase chances of recovery. ${ }^{20,21}$ This could be performed by a trained practitioner with local injections of $8 \mathrm{mg}$ of methylprednisolone or triamcinolone mixed with lidocaine into the nodule. Ultrasound guidance may be used to assist with the injection to clarify the anatomy. The injection may be repeated every 6 weeks for a total of 3 injections in patients who do not experience an improvement by at least $50 \% .^{22}$ Studies have shown that glucocorticoid injections have lasting improvement effects ${ }^{23,24}$ with the lowest success rate noted in diabetic patients. However, we still see recurrence.

In 1 study, splinting was found to significantly reduce triggering by keeping the metacarpophalangeal (MCP) joints in a slight flexion. ${ }^{25}$ Taping the affected finger to an adjacent normal finger may also help to relieve the symptoms.

Primary care clinicians should consider referring patients with trigger finger to plastic surgery, a primary care sports medicine specialist, or other hand specialists if conservative treatment fails and a maximum of 3 trials of glucocorticoid injections show no significant improvements in the span of 18 months. Referral is also warranted if the provider is not comfortable with steroid injection to the stenosing tenosynovitis.

\section{Hand and Wrist Laceration}

Trauma to the hand is 1 of the most common presentations in an acute setting, and lacerations are a big portion of these, many of which do not need a plastic or hand surgeon. Patients with acute laceration often seek treatment at the emergency department; however, patients living in rural areas with decreased access to the emergency department (ED) choose to go to their primary care clinician for their repair and follow-up due to convenience and trust in their care. ${ }^{26-28}$

The first step in the assessment of a hand and/or laceration is to perform a neurovascular examination of the injured hand. As mentioned previously, if the radial and ulnar pulses are not felt, a Doppler ultrasound study of the arteries is warranted. Next, a sensory examination in the distribution of the radial, median, and ulnar nerves should be done, followed by a full motor examination and assessment of deeper structures (flexor or extensor tendons). In general, all patients with significant hand trauma that have sustained a laceration and/or suspected motor or sensory injury should have a 3-view radiograph done. In cases of fractures, they are referred to a plastic/hand surgeon for further evaluation for reduction and possible surgical intervention. ${ }^{29,30}$ The patient should be asked about the timing and mechanism of the laceration, hand dominance, and patient occupation in addition to a tetanus vaccination and allergy history. Next, the wound depth, shape, and location should be noted. If there is active bleeding, pressure will be needed to achieve hemostasis first, and if this is not successful, then suturing may be necessary. For any bleeding, the practice is to hold firm pressure for 15 minutes $\times 2$ before continuing with any further intervention. Achieving hemostasis is important for many reasons, 1 of which is to allow for examination of the depth of the laceration, tendon function, and prevent any hematoma formation. Necrotic tissue, foreign bodies, and debris should be removed with irrigation. Irrigating with $100 \mathrm{~mL}$ of saline or tap water ${ }^{31}$ per $1 \mathrm{~cm}$ of laceration length is recommended. ${ }^{32}$ Suspected foreign bodies that are not identified visually will need imaging as needed. As discussed previously, wound depth assessment plays a key role in management; full-thickness wounds require further evaluation and treatment by a specialist. In patients with lacerations sparing deeper structures of the hand such as tendons, muscles, vasculature, bones, nerves, and nail beds, primary care clinicians could repair the wound and do not need to consult a specialist. Most lacerations in the fingers and hands can be performed by 4.0 chromic sutures, which are absorbable sutures and do not need to be removed. However, this could increase the risk for scars due to the absorbable nature, so if the patients are reliable and will come back for 
follow-up, 4.0 nylon are recommended. Nylon sutures need to be removed within 7 days of repair.

Complaints of tingling are common with hand or wrist lacerations due to digital nerve compression from trauma-related swelling. However, if present, referral to rule out nerve injury could be warranted.

Referral is recommended for a laceration resulting from a bite with an open wound over the metacarpophalangeal (MCP) joint or distal metacarpal neck. Other indications for referral include a dysvascular digit (capillary refill greater than 2 seconds), any signs of exposed bones, contamination, early infection, and associated fractures. If the physician is not able to close the soft tissue, referral to a hand surgeon is recommended. Partial-thickness lacerations should sometimes be closed in layers of suturing and in these situations, referral to the emergency department $(\mathrm{ED})$ is reasonable.

\section{Pressure Ulcers}

Pressure ulcers in the elderly are commonly seen in the outpatient general practice setting with an annual prevalence of $7 \%$ to $9 \%$ in the United States, especially in patients receiving home nursing services. ${ }^{33-35}$ When should these patients be referred to specialists?

Pressure ulcers tend to have a circular margin and are caused by tissue compression over a bony protuberance or by inadequate perfusion. The wound is formed after a decrease in blood supply to the tissue concerned, hypoxia, or vascular damage to the tissue arteries. ${ }^{36}$ Tissues with a compromised blood supply or oxygenation are at risk for ischemia, leading to necrotic tissue formation. Any necrotic tissue should be removed as it promotes bacterial growth and delays wound healing. The patient should also avoid too little or excessive moisture. Protecting peri-wound skin is helpful and most importantly, reducing pressure over the wound area. Treatment of pressure ulcers depends on wound staging as defined by the National Pressure Ulcer Advisory Panel ${ }^{37}$ (Table 1). Stage determination is based on the type of tissue visualized and palpated. Stage I will have intact skin with nonblanchable redness over a bony area. One way to detect Stage I ulcers in intact skin is by palpation, it might feel warmer or cooler than adjacent tissue. Stage II ulcers is characterized by a shallow pink or red wound bed or a serum-filled blister without bruising. In stage III ulcers, subcutaneous fat but no other tissue (tendons or bone)
Table 1. Wound Staging as Defined by the National Pressure Ulcer Advisory Panel

\begin{tabular}{|c|c|}
\hline Stage & Description \\
\hline I & Erythematous skin with no lesions \\
\hline II & $\begin{array}{l}\text { Lesions affecting the dermis or parts of it } \\
\text { or presence of blisters }\end{array}$ \\
\hline III & Full-thickness wound only \\
\hline IV & $\begin{array}{l}\text { Full-thickness wound with bone, joint, or } \\
\text { tendon involvement }\end{array}$ \\
\hline Unstageable & $\begin{array}{l}\text { Full-thickness wound with eschar at the } \\
\text { base }\end{array}$ \\
\hline
\end{tabular}

might be palpable or visible. In stage IV, tendons, muscles, or bones will be palpable or visible. Ulcers with eschar at the base are described as unstageable pressure ulcers.

Stage 1 wounds should be covered with transparent film and warrant immediate preventative treatment: minimize friction at the wound site, using pressure-reducing products and correcting any existing malnutrition.

Stage 2 wound treatment consists of a moist dressing over the wound dressing. If necrotic tissue is present, consider occlusive dressings such as hydrogels to promote dead tissue enzyme digestion (autolytic debridement) rather than manual debridement.

Similar to partial-thickness burns, stages 1 and 2 wounds can be treated in the primary care clinician's outpatient clinic. As previously discussed, steps in management include evaluation of the wound, history of vaccination, timing and mechanism of injury then bleeding control. Stage 3 and 4 wounds require debridement with a dressing, antibiotics if infected, then referral to the emergency department.

\section{Venous Wounds}

The overall prevalence of venous wounds is $3 \%$ in patients who are 65 years or older. Primary care clinicians are very likely to encounter patients with such presentation. ${ }^{38,39}$ Venous wounds occur in the setting of venous valve dysfunction with failure to return blood from the legs to the heart causing venous congestion, edema, and limb staining. ${ }^{40}$

Venous wounds tend to have irregularly shaped margins located in the ankle or midcalf, commonly occurring in older adults. They are usually shallow, painful, large, and can have granulation tissue at the 
base. Unlike pressure ulcers, venous wounds should be initially treated with compression. Like pressure ulcers, necrotic tissue should be removed, protecting the peri-wound skin and ensuring lower-extremity moisturization is important.

Recommendations to the patient include leg elevation to minimize edema (30 minutes, 3 or 4 times per day) and using Pentoxifylline (Trental) or Aspirin in conjunction with compression therapy. ${ }^{41}$

\section{Arterial Wounds}

Age is a risk factor for arterial wounds, with a $3.5 \%$ prevalence in patients who are 80 to 89 years old. Arterial insufficiency is the leading cause and is often missed due to the absence of symptoms. $^{42}$

Arterial wounds occur due to ischemia in the context of an arterial occlusive disease. Arterial and diabetic wounds are both painful and might look similar to nonwound specialists. They are most often located in the toes and feet (distal arterial circulation) and have well-defined borders on a pale wound bed with little to no granulation.

For diagnosis, the limb affected will feel cold to touch and 1 may only feel a faint pulse with a delayed capillary refill. Arterial wounds are very painful, especially at night. Unlike diabetic wounds, arterial wounds will have a pathologic ankle-brachial index $<0.9$. An ankle-brachial index $<0.9$ is thus considered a diagnostic test. ${ }^{43}$

One way to ease the pain is to put the affected limb over a stand (chair or bed) to allow gravity to pull the blood toward the wound. Primary care clinicians can screen patients for risk factors and initiate preventative measures and treatment early. ${ }^{44}$ Risk factors such as obesity, limited joint mobility, high blood pressure, and renal disease should be managed aggressively and as soon as possible to prevent further worsening of the wound. Primary care clinicians should consider frequent hand and foot exams for any unusual changes in color or sore development.

Besides controlling their modifiable risk factors, primary care clinicians can control bioburden, remove callous formed on a regular basis, or recommend an off-loading shoe to remove pressure from the wound. Since arterial wounds are considered ischemic wounds, they should remain dry to decrease any chances of infection. ${ }^{43}$
When identified, an arterial wound with poor perfusion and no improvements with conservative treatment warrants referral for vascular evaluation. If perfusion is intact or only mildly impacted, a wound assessment and classification should be conducted as described in the previous section to decide whether referral to a plastic surgeon is warranted.

\section{Diabetic Wounds}

Diabetic wounds, also known as neuropathic wounds, occur due to hyperglycemia-induced damage to the motor and sensory nerves in the extremities. With a prevalence of $6.3 \%$, they are commonly seen in the primary care setting. ${ }^{45}$ Regular examination of the extremities is key. Early signs of wound formation include 2 or more symptoms of inflammation (erythema, swelling, and tenderness). ${ }^{46}$ If infection is suspected on wound examination, cultures should be sent and empiric therapy along with risk factor control management should be started.

Treatment of mild infections of diabetic wounds consists of antibiotics against skin flora organisms such as streptococci and S. aureus (MSSA and MRSA). ${ }^{47}$ Antibiotic therapy should be continued until the infection resolves. Follow-up is essential, a decrease in inflammatory markers is a good sign for ongoing resolution of wound infections.

Wound dressing should be changed daily and plays a role in increasing autolytic debridement and maintaining any healthy skin around the wound:

- For dry wounds, hydrocolloid dressing is recommended.

- For exudative wounds, calcium alginates such as kaltostat or hydrofiber dressings such as aquacel are recommended.

- For any wounds covered by eschar, consider consulting a wound specialist.

Primary care clinicians can also recommend hyperbaric oxygen therapy for chronic wounds due to its anti-inflammatory and antibacterial benefits. ${ }^{48}$ Patient education is an important factor in reducing the number of delayed presentations, patients may not fully understand the severity of diabetic wound complications.

All patients with an enlarging diabetic wound refractory to the conservative treatments described above or with deep ulcers reaching muscle or bony 
tissue should be evaluated as soon as possible by a wound specialist to assess for any necessary debridement or soft-tissue reconstruction. Other productive consultations include endocrinology, nephrology, nutrition, podiatry, and infectious disease if any infections arise.

Moderate-to-severe infections that present with abscesses, necrosis, or signs of osteomyelitis (visible bone or wound larger than $2 \mathrm{~cm}^{2}$ ) require immediate surgical referral; early debridement in those patients have shown better outcomes compared with those who received antibiotic treatment before surgery. ${ }^{49}$

\section{Lymphedema}

Around 250 million patients worldwide suffer with lymphedema. ${ }^{50}$ Lymphatic dysfunction can be due to a congenital structural abnormality or due to a secondary cause from radiation, surgery, or burn. ${ }^{51}$ Lymphatic dysfunction causes serum proteins and water to leak into the interstitial space, leading to the formation of lymphatic fluid, which is taken to the blood steam through the lymph system. Lymph channels become clogged and block flow of fluid leading to fibrosis and inflammation. ${ }^{52}$ The diagnosis of lymphedema is clinical.

Lymphedema is undertreated and underdiagnosed and unfortunately has a great impact on wound healing.

Lymphedema is classified into 4 stages (0, I, II, and III). The International Society of Lymphology considers 2 criteria, soft-tissue fibrosis (ie, "softness or firmness") and outcome after elevation for classification. ${ }^{53}$ On physical examination it is important to palpate the soft tissue involved and to evaluate skin color, temperature, and to look for any weepy exudates. ${ }^{53}$ Patient education about skin hygiene to reduce infection and maximize wound healing is imperative.

Intervention should start as soon as stage I has developed. Decongestive therapy should be the firstline treatment. ${ }^{53}$ Decongestive therapy is usually performed by a physical therapist and consists of manual lymphatic drainage and limb compression. Primary care clinicians should encourage physical activity as this helps with drainage. Wearing compression sleeves decreases any fluid accumulation. The use of an arm pump by the patient to increase fluid flow is recommended. Diuretics and benzopyrones are not recommended. ${ }^{54}$ Contraindications to physiotherapy include diabetes, heart failure, acute infections, and deep venous thrombosis.
Referral is warranted for patients who progress to stage III for evaluation, possible microsurgery, or lymph-node excision.

\section{Skin Tears}

A skin tear most commonly occurs in the setting of trauma to the skin such as hitting a car door or via skin stripping by tape removal or lacerations from twisting forces applied to the skin. The upper extremities are the most common site of injury. The incidence of skin tears is inversely correlated to skin moisturization and internal hydration. ${ }^{55}$ Thus, primary care clinicians play a vital role in preventing skin tears in susceptible populations, especially the elderly. For example, encouraging fluid intake in patients on steroid medication is essential for skin integrity.

Plastic surgeons offer a wide variety of treatments such as lasers and minimally invasive procedures to improve scar appearance. ${ }^{56}$

When a patient comes in with a skin tear, identifying the causative factor is key. Asking about the hydration status and use of topical moisturizing agents is helpful for identifying any nonobvious causative factors. By treating these underlying causes, further skin damage is less likely to occur. Primary care clinicians can initiate treatment by choosing moist dressings such as aquaphor, hydrogel, or bacitracin. In general, skin tears heal relatively quickly. Depending on the severity of the wound, one should expect skin tears to heal after 7 to 21 days. ${ }^{57}$ If the timespan is prolonged and the tear has not improved despite appropriate initial treatment in a patient with no other significant comorbidities, referral to a wound specialist is warranted. Patients with open fractures, tendon, nerve, muscle lesions, or skin tears in the eyelids are recommended to be referred to plastic surgery or a reconstructive specialist.

\section{Scar Management}

Plastic surgeons are commonly consulted for scar management and revisions. However, primary care clinicians can manage, treat, and prevent scars in the outpatient setting before a plastic surgeon is needed.

A scar is composed of fibrous tissue, it is the replacement of normal skin tissue after it has healed by resolution. Scars look very different from one another due to size, depth, anatomic location, and the quality of wound care received. 
The main scar types include "flat" cicatrix, widespread, atrophic, hypertrophic, keloid, and contracture scars. ${ }^{58}$

- Acutely, flat scars will appear raised, pink, and may be pruritic before flattening. Most scars with appropriate wound care will result in a flat scar with no further management indicated.

- Widespread scars are asymptomatic, flat, and pale. They usually appear 3 weeks after surgery due to gradual stretching.

- Abdominal striae, a subtype of widespread scars, is seen in pregnancy.

- Atrophic scars, also known as "depressed" scars, are commonly seen after varicella or acne. These scars will usually be round with a depressed center.

- Hypertrophic scars, unlike previous ones, are raised. The scar will be red and painful with hypertrophy limited to the site of the original lesion. Hypertrophic scars are classically seen after burn injuries and tend to show some spontaneous regression over time.

- Keloid scars are also raised but grow beyond the boundaries of the original lesion. These scars will gradually grow without any spontaneous regression.

- Contracture scars typically occur at joints and skin in folds. Due to the skin angle formed at those sites, the scar contracts and thickens and is not considered fully healed. The scar will be raised and appear to be "pulling" the surrounding skin causing loss or decreased function of the joint.

Scar type dictates management; however, not all scars require treatment. A structured scar assessment including into the site of the scar, associated symptoms, degree of functional impairment, and patient disturbance can be helpful in deciding whether treatment is indicated or not. ${ }^{58}$ An example of a concerning scar assessment would consist of a large scar located at the sternum with continuous inflammation with poor response to first-line treatments. Validated scar assessment calculators exist in the literature. The Vancouver scar scale and the Manchester scar proforma are 2 examples to evaluate scar severity. ${ }^{59}$

Subjective evaluation by the primary care clinician is also possible and can be done at presentation; this is especially convenient at busy practices. Before starting any treatment, it is important to know that most plastic surgeons evaluate patients for scar revision after at least 6 months, but preferably after a 1 year of any wound. This is to allow the body to undergo all 3 stages of normal wound healing (inflammation, proliferation, and remodeling). Many scars disappear or are very subtle after a year and do not require any treatment. ${ }^{60}$ Primary care clinicians can start noninvasive treatments on diagnosis. This includes compression therapy, dynamic and static splints, antihistamines, and hydrotherapy. ${ }^{58}$

Compression therapy increases collagen maturation and reduces capillary perfusion pressure, leading to flattening of the scar. Static splints minimize contracture by creating a mechanical force that opposes the contractile force within the wound. ${ }^{61}$ Dynamic splints consist of prolonged and repeated stretching of the skin, leading to connective tissue elongation and scar enhancement. ${ }^{62}$ Antihistamine creams decrease scars' growth rate thanks to their antiinflammatory properties and inhibitory effect on collagen synthesis. ${ }^{63}$ Hydrotherapy uses pressurized warm water to remove any gross contaminants, toxic debris, and bacteria at the scar site. This helps eliminate sources of inflammation. ${ }^{64}$

If the structured scar assessment is not concerning, it is best to observe and reassure without any interventions before re-evaluation. For any fresh wound, it is also important to discuss scar prevention with patients. Patients should:

- Avoid sun exposure as much as possible for 1 year. Use of broad-spectrum sunscreen with an SPF of 30 or higher should be encouraged.

- Use of skin tape can be used across minor wounds to reduce tensile strength, allowing for "approximation without tension." The skin tension and blood supply of a wound are the two most important factors in minimizing scar formation.

- Avoid infection or contamination in the wound.

- Stay hydrated.

- Avoid smoking and alcohol, and optimize nutrition status.

- Avoid putting stress on the wound.

Moreover, we also advise educating patient that certain areas of the body are more prone to severe scars, including the ears, the top of the shoulder, and the area in front of the breastbone (sternum). ${ }^{65}$ Further, compared with younger patients, older individuals are less prone to the formation of hypertrophic scars given their decrease in skin elasticity and tension. ${ }^{66}$ Discussing these factors with the patient will allow for congruent expectations for each visit.

Referral to a plastic surgeon for evaluation and treatment is only warranted for scars that have been present for at least 6 months or preferably close to 1 year with a concerning scar assessment. ${ }^{58}$ Keloids, 
Table 2. Indications for Referral and Initial Management

\begin{tabular}{|c|c|c|}
\hline & Indications for Referral & Initial Management in the Office \\
\hline Hand burn & $\begin{array}{l}\text { Partial-thickness burns }>10 \% \text { of TBSA } \\
\text { Third-degree burns } \\
\text { Burns involving major joints } \\
\text { Chemical or electrical burns } \\
\text { Inhalation injury or concomitant trauma } \\
\text { Special social, emotional, or rehabilitation needs }\end{array}$ & $\begin{array}{l}\text { Apply dressings including bacitracin, mafenide } \\
\text { acetate (sulfamylon), mupirocin (Bactroban), } \\
\text { aquacel, biobrane, hydrocolloids, mepilex, } \\
\text { xeroform, or acticoat }^{7}\end{array}$ \\
\hline Trigger finger & $\begin{array}{l}\text { Conservative and steroid treatments show no } \\
\text { improvements. Provider is not comfortable } \\
\text { with steroid injection to the stenosing } \\
\text { tenosynovitis. }\end{array}$ & $\begin{array}{l}\text { Activity modification } \\
\text { Splinting } \\
\text { Short-term nonsteroidal anti-inflammatory } \\
\text { drugs }\end{array}$ \\
\hline Hand laceration & $\begin{array}{l}\text { Bite } \\
\text { Laceration caused by teeth } \\
\text { Capillary refill greater than } 2 \text { seconds } \\
\text { Exposed bones } \\
\text { Contamination, early infection, and associated } \\
\text { fractures } \\
\text { Provider unable to close the soft tissue }\end{array}$ & $\begin{array}{l}\text { Neurovascular exam } \\
\text { Sensory exam } \\
\text { Motor exam } \\
\text { Achieve hemostasis with pressure } \\
\text { Irrigation with sterile or tap water } \\
\text { Soft-tissue closure }\end{array}$ \\
\hline Pressure ulcers & Stage 3 and 4 wounds & $\begin{array}{l}\text { Wound evaluation and staging } \\
\text { Bleeding control } \\
\text { Pressure reduction } \\
\text { Correct any existing malnutrition } \\
\text { Occlusive dressings }\end{array}$ \\
\hline Venous wounds & Necrotic tissue debridement & $\begin{array}{l}\text { Compression and leg elevation } \\
\text { Aspirin } \\
\text { Pentoxifylline }\end{array}$ \\
\hline Arterial wounds & $\begin{array}{l}\text { Wound with poor perfusion } \\
\text { No improvements with conservative treatment }\end{array}$ & $\begin{array}{l}\text { Leg elevation } \\
\text { Management of modifiable risk factors }\end{array}$ \\
\hline Diabetic wounds & $\begin{array}{l}\text { Refractory to conservative treatments } \\
\text { Deep ulcers reaching muscle or bony tissue }\end{array}$ & $\begin{array}{l}\text { Wound culture } \\
\text { Antibiotic therapy } \\
\text { Dressing changes } \\
\text { Patient education } \\
\text { Management of risk factors }\end{array}$ \\
\hline Lymphedema & Stage III & $\begin{array}{l}\text { Decongestive therapy } \\
\text { Patient education }\end{array}$ \\
\hline Skin tears & $\begin{array}{l}\text { Open fractures, tendon, nerve, muscle lesions, or } \\
\text { skin tears in the eyelids } \\
\text { Delayed healing ( }>21 \text { days) }\end{array}$ & $\begin{array}{l}\text { Moist dressings: aquaphor, hydrogel, or } \\
\text { bacitracin. } \\
\text { Encourage fluid intake }\end{array}$ \\
\hline Scar management & $\begin{array}{l}\text { Scars present for more than } 1 \text { year } \\
\text { A concerning scar assessment } \\
\text { Keloids, recurrent scars, contracture scars, } \\
\text { atrophic scars, widespread scars, or patients } \\
\text { with a positive family history of abnormal } \\
\text { scarring }\end{array}$ & $\begin{array}{l}\text { Structured scar assessment } \\
\text { Subjective evaluation } \\
\text { Compression therapy } \\
\text { Dynamic and static splints } \\
\text { Antihistamines } \\
\text { Hydrotherapy }\end{array}$ \\
\hline
\end{tabular}

TBSA, Total body surface area.

recurrent scars, contracture scars, atrophic scars, widespread scars, or patients with a positive family history of abnormal scarring are indications for referral to a plastic surgeon after first-line treatment. Hypertrophic scars and scars with ambiguous diagnoses should be first treated with pressure therapy such as silicone gel sheeting for at least 12 hours with 15 to $25 \mathrm{mmHg}$ pressure every day for a minimum of 2 months before referral. Intralesional corticosteroid injections for severe scarring may be considered before referral. ${ }^{58}$ 


\section{Conclusion}

Burns, lacerations, and wounds are commonly encountered by primary care clinicians. Primary care clinicians play an important role in diagnosing, treating, and managing patients with such presentations. Table 2 summarizes the indications for referral and initial management of these presentations.

To see this article online, please go to: http://jabfm.org/content/ 33/5/799.full.

\section{References}

1. Finley CR, Chan DS, Garrison S, et al. What are the most common conditions in primary care? Systematic review. Can Fam Physician 2018;64:832-40.

2. McDermott KW, Weiss AJ, Elixhauser A. Burnrelated hospital inpatient stays and emergency department visits, 2013: statistical brief \#217. In: Healthcare cost and utilization project (HCUP) statistical briefs. Rockville MD: Agency for Healthcare Research and Quality; 2006.

3. Alharbi Z, Piatkowski A, Dembinski R, et al. Treatment of burns in the first 24 hours: simple and practical guide by answering 10 questions in a stepby-step form. World J Emerg Surg 2012;7:13.

4. Baxter CR. Management of burn wounds. Dermatol Clin 1993;11:709-14.

5. Schaefer TJ, Szymanski KD. Burn evaluation and management. Treasure Island FL: StatPearls; 2020.

6. Orgill DP, Piccolo N. Escharotomy and decompressive therapies in burns. J Burn Care Res 2009;30:759-68.

7. Kamolz LP, Kitzinger HB, Karle B, Frey M. The treatment of hand burns. Burns 2009;35:327-37.

8. Vaseline ${ }^{\varpi}$ Petrolatum Gauze. 2020. Available from: https://www.woundsource.com/product/vaselinepetrolatum-gauze.

9. Barillo DJ, Barillo AR, Korn S, Lam K, Attar PS. The antimicrobial spectrum of Xeroform ${ }^{\oplus}$. Burns 2017;43:1189-94.

10. Schulfer A, Blaser MJ. Risks of antibiotic exposures early in life on the developing microbiome. PLoS Pathog 2015;11:e1004903.

11. Dawson-Hahn EE, Rhee KE. The association between antibiotics in the first year of life and child growth trajectory. BMC Pediatr 2019;19:23.

12. Tang H, Lv G, Fu J, et al. An open, parallel, randomized, comparative, multicenter investigation evaluating the efficacy and tolerability of Mepilex $\mathrm{Ag}$ versus silver sulfadiazine in the treatment of deep partial-thickness burn injuries. J Trauma Acute Care Surg 2015;78:1000-7.

13. Palmieri TL, Greenhalgh DG. Topical treatment of pediatric patients with burns: a practical guide. Am J Clin Dermatol 2002;3:529-34.

14. Hartford C. Care of outpatient burns. In: Herndon D, ed. Total burn care. Philadelphia, PA: WB Saunders; 2020, 71.
15. Mertens DM, Jenkins ME, Warden GD. Outpatient burn management. Nurs Clin North Am 1997;32: 343-64.

16. Advanced burn life support providers manual. Chicago, IL: American Burn Association; 2015.

17. Advanced Trauma Life Support (ATLS) Student Course Manual. 9th ed. Chicago, IL: American College of Surgeons; 2012.

18. Pencle FJ, Waheed A, Molnar JA. Trigger thumb. Treasure Island, FL: StatPearls; 2020.

19. Saldana MJ. Trigger digits: diagnosis and treatment. J Am Acad Orthop Surg 2001;9:246-52.

20. Baek GH, Kim JH, Chung MS, Kang SB, Lee YH, Gong HS. The natural history of pediatric trigger thumb.J Bone Joint Surg Am 2008;90:980-5.

21. Fiorini HJ, Tamaoki MJ, Lenza M, Gomes Dos Santos JB, Faloppa F, Belloti JC. Surgery for trigger finger. Cochrane Database Syst Rev 2018;2:CD009860.

22. Schubert C, Hui-Chou HG, See AP, Deune EG. Corticosteroid injection therapy for trigger finger or thumb: a retrospective review of 577 digits. Hand (New York, NY) 2013;8:439-44.

23. Rozental TD, Zurakowski D, Blazar PE. Trigger finger: prognostic indicators of recurrence following corticosteroid injection. J Bone Joint Surg Am 2008;90:1665-72.

24. Anderson B, Kaye S. Treatment of flexor tenosynovitis of the hand ('trigger finger') with corticosteroids. A prospective study of the response to local injection. Arch Intern Med 1991;151:153-6.

25. Colbourn J, Heath N, Manary S, Pacifico D. Effectiveness of splinting for the treatment of trigger finger. J Hand Ther 2008;21:336-43.

26. Young AP, Proctor DB. Kinn's the medical assistant: an applied learning approach. 10th ed. St Louis, MO: Saunders; 2007.

27. Townsend K. Fundamental concepts and skills for the patient care technician. 1st ed. St Louis, MO: Mosby; 2017.

28. Lambert C, Goldman RD. Pain management for children needing laceration repair. Can Fam Physician 2018;64:900-2.

29. Cheung K, Hatchell A, Thoma A. Approach to traumatic hand injuries for primary care physicians. Can Fam Physician 2013;59:614-8.

30. De Smet AA, Doherty MP, Norris MA, Hollister MC, Smith DL. Are oblique views needed for trauma radiography of the distal extremities? AJR Am J Roentgenol 1999;172:1561-5.

31. Gannon R. Wound cleansing: sterile water or saline? Nurs Times 2007;103:44-6.

32. Wheeler CB, Rodeheaver GT, Thacker JG, Edgerton MT, Edilich RF. Side-effects of high pressure irrigation. Surg Gynecol Obstet 1976;143:775-8.

33. Bergquist S, Frantz R. Braden scale: validity in community-based older adults receiving home health care. Appl Nurs Res 2001;14:36-43. 
34. Ferrell BA, Josephson K, Norvid P, Alcorn H. Pressure ulcers among patients admitted to home care. J Am Geriatr Soc 2000;48:1042-7.

35. Schwien T, Gilbert J, Lang C. Pressure ulcer prevalence and the role of negative pressure wound therapy in home health quality outcomes. Ostomy Wound Manage 2005;51:47-60.

36. Fogerty M, Guy J, Barbul A, Nanney LB, Abumrad NN. African Americans show increased risk for pressure ulcers: a retrospective analysis of acute care hospitals in America. Wound Repair Regen 2009; 17:678-84.

37. Edsberg LE, Black JM, Goldberg M, McNichol L, Moore L, Sieggreen M. Revised National Pressure Ulcer Advisory Panel Pressure Injury Staging System: Revised Pressure Injury Staging System. J Wound Ostomy Continence Nurs 2016;43:585-97.

38. Xie T, Ye J, Rerkasem K, Mani R. The venous ulcer continues to be a clinical challenge: an update. Burns Trauma 2018;6:18.

39. Kahle B, Hermanns HJ, Gallenkemper G. Evidencebased treatment of chronic leg ulcers. Dtsch Arztebl Int 2011;108:231-7.

40. Raffetto JD, Marston WA. Venous ulcer: what is new? Plast Reconstr Surg 2011;127:279S-288S.

41. O'Meara S, Cullum N, Nelson EA, Dumville JC. Compression for venous leg ulcers. Cochrane Database Syst Rev 2012;11:CD000265.

42. Rabbia J. Impaired integumentary integrity. Geriatric physical therapy. 3rd ed. St. Louis, MO: Mosby; 2012.

43. Grey JE, Harding KG, Enoch S. Venous and arterial leg ulcers. BMJ 2006;332:347-50.

44. Owen RS, Carpenter JP, Baum RA, Perloff LJ, Cope C. Magnetic resonance imaging of angiographically occult runoff vessels in peripheral arterial occlusive disease. N Engl J Med 1992;326:1577-81.

45. Zhang P, Lu J, Jing Y, Tang S, Zhu D, Bi Y. Global epidemiology of diabetic foot ulceration: a systematic review and meta-analysis. Ann Med 2017;49: 106-16.

46. Caputo GM, Cavanagh PR, Ulbrecht JS, Gibbons GW, Karchmer AW. Assessment and management of foot disease in patients with diabetes. N Engl J Med 1994;331:854-60.

47. Karchmer AW, Gibbons GW. Foot infections in diabetes: evaluation and management. Curr Clin Top Infect Dis 1994;14:1-22.

48. Roeckl-Wiedmann I, Bennett M, Kranke P. Systematic review of hyperbaric oxygen in the management of chronic wounds. Br J Surg 2005;92:24-32.

49. Tan JS, Friedman NM, Hazelton-Miller C, Flanagan JP, File TM, Jr. Can aggressive treatment of diabetic foot infections reduce the need for above-ankle amputation? Clin Infect Dis 1996;23:286-91.
50. Schulze H, Nacke M, Gutenbrunner C, Hadamitzky C. Worldwide assessment of healthcare personnel dealing with lymphoedema. Health Econ Rev 2018;8:10.

51. Szuba A, Rockson SG. Lymphedema: classification, diagnosis and therapy. Vasc Med 1998;3:145-56.

52. Taylor AE. Capillary fluid filtration. Starling forces and lymph flow. Circ Res 1981;49:557-75.

53. International Society of Lymphology. The diagnosis and treatment of peripheral lymphedema: 2013 Consensus Document of the International Society of Lymphology. Lymphology 2013;46:1-11.

54. Casley-Smith JR, Morgan RG, Piller NB. Treatment of lymphedema of the arms and legs with 5,6-benzo[alpha]-pyrone. N Engl J Med 1993;329:1158-63.

55. LeBlanc K, Baranoski S. Skin tears: state of the science: consensus statements for the prevention, prediction, assessment, and treatment of skin tears ${ }^{(}$. Adv Skin Wound Care 2011;24:2-15.

56. Scar Revision. 2020. Available from: https://www. plasticsurgery.org/reconstructive-procedures/scarrevision.

57. Payne RL, Martin ML. The epidemiology and management of skin tears in older adults. Ostomy Wound Manage 1990;26:26-37.

58. Bayat A, McGrouther DA, Ferguson MW. Skin scarring. BMJ 2003;326:88-92.

59. Powers PS, Sarkar S, Goldgof DB, Cruse CW, Tsap LV. Scar assessment: current problems and future solutions. J Burn Care Rehabil 1999;20:54 60; discussion 53.

60. Werdin F, Tenenhaus M, Becker M, Rennekampff HO. Healing time correlates with the quality of scaring: results from a prospective randomized control donor site trial. Dermatol Surg 2018;44:521-7.

61. Schouten HJ, Nieuwenhuis MK, van Zuijlen PP. A review on static splinting therapy to prevent burn scar contracture: do clinical and experimental data warrant its clinical application? Burns 2012;38:19-25.

62. Berner SH, Willis FB. Dynamic splinting in wrist extension following distal radius fractures. J Orthop Surg Res 2010;5:53.

63. Edriss AS, Mestak J. Management of keloid and hypertrophic scars. Ann Burns Fire Disasters 2005;18:202-10.

64. Hess CL, Howard MA, Attinger CE. A review of mechanical adjuncts in wound healing: hydrotherapy, ultrasound, negative pressure therapy, hyperbaric oxygen, and electrostimulation. Ann Plast Surg 2003;51:210-8.

65. Winter GD. Some factors affecting skin and wound healing. J Tissue Viability 2006;16:20-3.

66. Son D, Harijan A. Overview of surgical scar prevention and management. J Korean Med Sci 2014;29:751-7. 